\title{
PSICOLOGIA E SERVIÇO SOCIAL: ATENDIMENTOS ESSENCIAIS FRENTE À PANDEMIA DA COVID-19
}

\section{ARTIGO ORIGINAL}

BRUMATI, Lêda Cristiane dos Santos ${ }^{1}$

MARTINS, Nathiele da Silva ${ }^{2}$

BRUMATI, Lêda Cristiane dos Santos. MARTINS, Nathiele da Silva. Psicologia e serviço social: Atendimentos essenciais frente à pandemia da Covid-19. Revista Científica Multidisciplinar Núcleo do Conhecimento. Ano 05, Ed. 08, Vol. 14, pp. 1420. Agosto de 2020. ISSN: 2448-0959, Link de acesso: https://www.nucleodoconhecimento.com.br/saude/atendimentos-essenciais

\section{RESUMO}

O presente artigo é o resultado de uma pesquisa bibliográfica que que conduz ao estudo teórico e tem por objetivo apresentar a importância dos profissionais da psicologia e serviço social nos atendimentos individuais frente a disseminação da pandemia do Novo Coronavírus haja visto que a problemática enfrentada pela população frente a essa disseminação da doença pode vir a desenvolver doenças de aspecto mental e/ou social, ocasionando vulnerabilidade. O objetivo é demonstrar que

1 Especialista em: Gestão da Educação Pública pela Universidade Federal de Mato Grosso; Psicopedagogia Institucional pela Educon-Sociedade de Educação Continuada; Educação a Distância, Tutoria, Metodologia e Aprendizagem pela Educon-Sociedade de Educação Continuada; Educação Infantil e Séries Iniciais pela Educon-Sociedade de Educação Continuada; Licenciada em Pedagogia pela Universidade Federal de Mato Grosso; Bacharel em Serviço Social pelo Centro Universitário da Grande Dourados/MS.

${ }^{2}$ Especialista Gestão da Saúde - Instituto Prominas; Graduada em Psicologia pelo Centro Universitário da Grande Dourados/MS. 
tanto os profissionais da psicologia quanto do serviço social estão engajados em auxiliar na superação deste novo desafio imposto a área científica e a todo contingente populacional. No que tange aos resultados desta pesquisa foi possível verificar que os atendimentos desses profissionais são de extrema relevância e assim conclui-se que tal atuação permite a garantia do bem estar mental e social da população frente as mudanças no cotidiano durante a pandemia

Palavras-chave: Pandemia, proteção, saúde.

\section{INTRODUÇÃO}

Este trabalho se refere à importância dos atendimentos psicossociais frente a pandemia da Covid-19, levando-se em consideração que os profissionais da psicologia e serviço social tem se esforçado para buscar respostas às mais variadas demandas de todo o país, haja visto que estes trabalham diretamente com a população nas diferentes políticas públicas sociais e equipamentos públicos e que estão na linha de frente no combate à Covid-19 e em defesa do direito à vida. (BRASIL, 2020). Tal afirmação vem de encontro com o prescrito nos protocolos de manejo clínico e de atendimento na atenção básica.

Fez-se imperativo destacar a atuação desses profissionais tem no exercício da função, em especial para aqueles que atuam em unidades de saúde, pois é sabido que tanto a psicologia quanto o serviço social tem por sua conduta ética atuar em situações de calamidade pública, exercendo em consonância com a legislação profissional vigente e não expondo a si mesmo a riscos, seguindo os protocolos de segurança emitidos por órgãos competentes, neste sentido, frente ao combate à pandemia em questão. 


\section{DESENVOLVIMENTO}

\section{DESAFIOS NO COMBATE AO CONTÁGIO}

Há de se considerar que o novo Coronavírus trouxe repercussões alarmantes que impactaram diretamente no mundo como um todo. Profissionais envolvidos das diversas áreas buscam contribuir para com a diminuição do contágio e da resolutiva em um tratamento que possa combater essa pandemia.

Neste sentido fazem parte também desta equipe de profissionais o(a) Assistente Social e o(a) Psicólogo(a). Esses profissionais tem importante papel nas ações desenvolvidas nos hospitais e unidades básicas de saúde, cabendo a eles, garantir atendimento psicossocial não só para trabalhar a questão social e mental, abrangendo ainda que seja resguardado os direitos de acesso às políticas públicas, que possam de fato atender de forma integral o cidadão, pois é sabido que frente ao caos disseminado pela doença 0 atendimento que já era fragilizado, piorou significativamente, expondo as pessoas que necessitam a uma situação muito mais vulnerável.

Ante o exposto compete elencar que de acordo com Ujvari (2011) já se temia uma pandemia de tamanho catastrófico, que atingisse o mundo todo e que teria grande poder mortal, bem como poder de contágio infectando grande números de pessoas, o que geraria o caos global.

E o que se receava, aconteceu. Inúmeros contágios, colocando em risco toda população. Equipes médicas, cientistas, estudiosos em geral buscando respostas, trabalhando incansavelmente para atender uma demanda altíssima e até então misteriosa. De imediato inclui-se os atendimentos de psicologia e serviço social para que nesse contexto, esses profissionais possam fazer o contato, a mediação com a equipe médica, para que cada situação tenha um resultado positivo e assim possibilitar o desempenho da assistência humanizada, cujas atuações fazem parte da equipe multidisciplinar garantindo ampla assistência aos pacientes que em sua grande maioria estão mais presentes nos espaços em maior vulnerabilidade social e 
econômica, onde por conta da pandemia da Covid-19, muitos desses profissionais desempenham suas atividades cotidianas e agregam também ações na linha de frente na garantia dos direitos humanos daqueles que mais precisam.

O maior desafio além da descoberta de uma vacina eficaz está também ampliar o atendimento para pessoas que estão expostas a níveis de sofrimento mais severos relacionados à pandemia, incluem-se aqui pessoas com suspeita ou diagnóstico confirmado e seus familiares, pois segundo Antunes (2009), sempre ouve um forte apelo em se discorrer sobre como nosso sistema imunológico enfrentaria novas doenças, pois ainda há muitos elementos a se descobrir, compreender e buscar uma eficácia coerente ao enfrentamento dos agentes nocivos à saúde, que estão em larga escala seja sob forma viral, bacteriana dentre outras presentes no ambiente natural ou produzidos pelo homem.

É imprescindível destacar ainda como um desafio o fortalecimento do sistema imunológico bem como da saúde mental. Mas é preciso considerar ainda que na constância auxiliar não só a população, mas também as empresas a combater a disseminação da doença no ambiente laboral, identificar casos suspeitos, formas de transmissão e grupos de maior risco para a Covid-19. Seria bom que todos obtivessem um plano de contingenciamento da doença pois conhecimento e prevenção auxiliam e muito no combate à pandemia.

\subsection{PROCESSOS DE INTERVENÇÕES: BREVE RELATO SOBRE AS AÇÕES DOS ASSISTENTES SOCIAIS E PSICÓLOGOS NA SAÚDE}

Compete destacar que 0 profissional de psicologia tem por sua competência identificar e intervir nos fatores determinantes das ações e dos sujeitos, pondera a extensão de fatores hereditários, ambientais e psicossociais e como se incide a dinâmica intrapsíquica nas suas relações com o todo, pautando-se em um atendimento que visa promover a saúde mental na prevenção e no tratamento dos distúrbios mentais, seja preexistente, ou que surja no período de vivencia do sujeito, pautando-se em oportunizar amplo desenvolvimento psicossocial. 
De forma sintetizada elenca-se ainda as atribuições do profissional de serviço social que é responsável em colaborar para promover aos usuários o bem estar físico, psicológico e social. E para isso é prioritário o atendimento direto aos usuários, realizando ações psicossociais e socioassistenciais; ações de articulação com a equipe de saúde e institucionais e ações socioeducativas, cuja participação na elaboração de projetos de educação permanente é fundamental. Salienta-se ainda que esse profissional está sempre atento no que se refere a fiscalização e gestão das políticas de saúde, com vistas a garantir a execução dos direitos conquistados pelos usuários. Realiza orientações (individuais e coletivas) que culminam na contribuição para a defesa das políticas públicas de saúde eficientes, para assim buscar assegurar os direitos sociais. Há que se mencionar que a abrangência da atuação desses profissionais (psicologia e serviço social) trazem em seus bojos inúmeras outras ações aqui não explicitadas, haja visto que novas adequações na frente de trabalho são feitas , como no que tange as ações neste período de pandemia, onde dentre os possíveis desafios para o processo de intervenção psicossocial na vigência da pandemia de COVID-19 no Brasil, pode ser mencionado a restrição a deslocamentos e a necessidade de realização de serviços de atendimento predominantemente por meios de tecnologia da informação e da comunicação, haja visto que nesta atual conjuntura as equipes de saúde em especifico profissionais da psicologia e serviço social desempenham ainda intervenções voltadas à população geral que incluem além dos atendimentos respeitando as normas dos seus respectivos Conselhos, ações de divulgação sobre formas de prevenção, isolamento social em orientações prescritas em materiais informativos bem como trabalho orientativo nas barreiras sanitárias e locais de possível fluxo de pessoas.

As estratégias de atuação se pautam no atendimento que auxilia aliviar em grandes proporções o impacto da doença na saúde mental e social dos afetados, tanto do caos psíquico, quanto no atendimento ao quadro orgânico, via atendimento humanizado que se torna essencial durante o período de quarentena, favorecendo modos mais efetivos de adaptação e enfrentamento. 
Para Soares (2019) a busca por proporcionar a um paciente o alívio de suas dores vai além da conduta médica e da equipe de profissionais cuidadores. É preciso que se a cura ainda não existe, se haja o respeito ao paciente de forma geral, dentro da sociedade e do âmbito familiar, para que assim se obtenha maior enfrentamento da doença.

Ressalta-se que se realiza também nesse contexto informações sobre estratégias para promoção de bem-estar físico, mental e social e ampla divulgação ocasião em que devem ser ofertadas condições adequadas de prevenção e proteção contra o Novo Coronavírus.

\subsubsection{MEDIDAS ADOTADAS QUE AUXILIAM NO COMBATE A PANDEMIA}

Em muitas cidades e/ou países foram determinadas algumas medidas que visam proteger a população bem como diminuir a disseminação do vírus. Neste contexto e em conformidade com a Lei 13.979/20, faz-se necessários apresentar algumas delas, em sendo:

Toque de recolher em municípios: $O$ objetivo é diminuir a circulação de pessoas nas ruas das cidades e assim evitar o contato e o possível contágio, haja visto que sem movimentação de pessoas se pode diminuir a propagação do vírus.

Suspensão de voos: Operando com redução de voos e assim diminuindo o trânsito de pessoas de outras lugares e/ou do próprio local.

Suspensão de eventos: Evitando-se aglomerações, reduzindo número de participantes em caso de haver.

Suspensão de aulas: Sejam em estabelecimentos públicos ou privados a medida visa contribuir para não disseminação do vírus, onde as unidades deverão reorganizar o calendário letivo cujas atividades deverão ser compensadas nos dias reservados para os recessos futuros. 
Obrigatoriedade das máscaras: Em muitas localidades há a aplicabilidade de uma Lei específica que determina que o uso obrigatório da máscara, evitando assim contágio.

Há que se considerar que além do uso de máscara faz parte da legislação o uso de álcool gel 70, que seja disposto à população nos comércios para assepsia.

Suspensão de visitas em unidades prisionais: em virtude do crescimento de número de contagiados nos presídios tal medida visa não expor os presos, os profissionais e também os visitantes.

Campanha de prevenção: informativos impressos, audiovisuais, web conferência, mídias em geral para alertar a população, não só sobre a doença em si, mas também sobre a prevenção.

Combate às fake News: Está em vigor em muitos Estados a Lei que pune autores, divulgadores, que expõem noticiam fake News sobre epidemias, endemias e pandemias, passivo de multa. (PL 2630/20).

\section{CONSIDERAÇÕES FINAIS}

A atuação psicossocial no contexto da pandemia do Coronavírus vem de encontro para com o processo de somar forças para o combate a proliferação da Covid-19, porém, é importante dizer que o desempenho é parte do processo, ela não se dá de forma heroica e isolada.

Em tempos de calamidade pública, a ação dos profissionais da psicologia e serviço social tem papel de destaque na linha de frente das atuações que possam diminuir o impacto da pandemia na vida da população, pois é sabido que frente a essa situação caótica do quadro de pandemia incide sobre implicações na saúde mental e social do indivíduo e neste aspecto o atendimento psicossocial constitui-se como um aliado ao enfrentamento da pandemia do novo Coronavírus. 
Neste sentido compreende-se que o atendimento psicossocial pode ser considerado grande emergência de saúde pública de nível internacional. Há que ponderarmos que esses atendimentos envolvem a realização de intervenções para minimizar implicações negativas e promover a saúde mental e social, bem como em tempos futuros, quando os indivíduos necessitarão se readaptar e lidar com as perdas e transformações como um todo, mais especificamente os indivíduos em maior vulnerabilidade socioeconômica.

É possível destacar que embora fora imposto desafios adicionais à atuação dos psicólogos e assistentes sociais no Brasil e no mundo, a pandemia do novo Coronavírus pode colaborar para que haja maior aprimoramento da prática e da pesquisa em situações de colapso, emergência e catástrofes.

\section{REFERÊNCIAS}

ANTUNES, L. J. Imunologia Básica. São Paulo: Atheneu, 2009.

BRASIL. Lei 13.979/20. Dispõe sobre as medidas para enfrentamento da emergência de saúde pública de importância internacional decorrente do Coronavírus responsável pelo surto de 2019.

Protocolo de manejo clínico do Coronavírus (COVID-19) na Atenção Primária à Saúde. Ministério da Saúde, 2020.

Protocolo de Tratamento do Novo Coronavírus (COVID-19). Ministério da Saúde 2020.

Projeto de Lei n²630/20 - Senado Federal, 2020.

SOARES, A.M. Enquanto eu respirar. Rio de Janeiro: Editora Sextante, 2019.

UJVARI, S. C. Pandemias: A humanidade em risco. São Paulo: Editora Contexto, 2011.

Enviado: Junho, 2020. 
Aprovado: Agosto, 2020. 